\title{
Article \\ Gender Differences in Knowledge and Attitude towards HPV and HPV Vaccine among College Students in Wenzhou, China
}

\author{
Gang Chen ${ }^{1}$, Biao Wu ${ }^{2}$, Xuchao Dai ${ }^{1}$, Mengqi Zhang ${ }^{1}$, Yupeng Liu ${ }^{1} \mathbb{D}$, Hong Huang ${ }^{1,3,4}$, Kun Mei $^{1,4,5, * \mathbb{D}}$ \\ and Zhigang $\mathrm{Wu}^{6,7, *}$
}

1 School of Public Health and Management, Wenzhou Medical University, Wenzhou 325035, China; chengang718@163.com (G.C.); XuchaoD1@163.com (X.D.); zhangmengqi324@163.com (M.Z.); liuyupeng@wmu.edu.cn (Y.L.); Huanghongpanda@163.com (H.H.)

2 School of Public Health, Fudan University, Shanghai 200032, China; wubiaozj@163.com

3 Center for Health Assessment, Wenzhou Medical University, Wenzhou 325035, China

4 Zhejiang Provincial Key Laboratory of Watershed Science and Health, Wenzhou Medical University, Wenzhou 325035, China

5 School of Geography Science and Geomatics Engineering, Suzhou University of Science and Technology, Suzhou 215009, China

6 Department of Urology, The First Affiliated Hospital of Wenzhou Medical University, Wenzhou 325035, China

7 Reproductive Health Research Center, Health Assessment Center of Wenzhou Medical University, Wenzhou 325000, China

* Correspondence: meikun@iwaterlab.com (K.M.); andrologywzg@wmu.edu.cn (Z.W.); Tel.: +86-0577-86699595 (K.M.); +86-0577-88069210 (Z.W.)

check for updates

Citation: Chen, G.; Wu, B.; Dai, X.; Zhang, M.; Liu, Y.; Huang, H.; Mei, K.; Wu, Z. Gender Differences in Knowledge and Attitude towards HPV and HPV Vaccine among College Students in Wenzhou, China. Vaccines 2022, 10, 10. https: / / doi.org/10.3390/vaccines 10010010

Academic Editors: Barbara Gardella and Zheng Quan Toh

Received: 13 October 2021

Accepted: 17 December 2021

Published: 22 December 2021

Publisher's Note: MDPI stays neutral with regard to jurisdictional claims in published maps and institutional affiliations.

Copyright: (C) 2021 by the authors. Licensee MDPI, Basel, Switzerland. This article is an open access article distributed under the terms and conditions of the Creative Commons Attribution (CC BY) license (https:// creativecommons.org/licenses/by/ $4.0 /)$.

\begin{abstract}
Objective: This study aimed to determine human papillomavirus (HPV)-related awareness and willingness to receive HPV vaccination among college students, in Wenzhou, and its associated factors. Methods: A cross-sectional epidemiological study was conducted among college students in Wenzhou to investigate their knowledge, attitude, and factors affecting their willingness to receive HPV vaccination. Results: A total of 1035 questionnaires were collected, of which 1002 were valid (males: 374, females: 628). In total, 904 (90.2\%) college students had heard of HPV, with a lower rate among males than females $(85.3 \%$ vs. $93.2 \%, p<0.05)$ and $693(69.2 \%)$ had heard of the HPV vaccine, with a significantly lower rate among males than females $(53.7 \%$ vs. $78.3 \%, p<0.05)$. Overall awareness of HPV and HPV vaccine among males and females was moderate, with lower awareness among males. A total of $55.9 \%$ of males and $80.4 \%$ of females indicated that they would be willing to receive the HPV vaccine, a significant difference $(p<0.001)$. The price, safety of HPV vaccine, and lack of knowledge about HPV and HPV vaccine were the major barriers to HPV vaccination for college students. Compared to females, inadequate knowledge of HPV was the main barrier factor for HPV vaccination among male college students. Conclusions: The overall knowledge level of males is lower than that of females. For male college students, providing more knowledge about HPV infection is helpful to promote their willingness to vaccinate. It is necessary to promote HPV-related knowledge for male and female college students, respectively.
\end{abstract}

Keywords: human papillomavirus; HPV vaccine; college students; knowledge; survey

\section{Introduction}

Human papillomavirus (HPV) is a highly infectious virus that is transmitted primarily through sexual intercourse and is one of the most common sexually transmitted infections (STI) in the world [1,2]. HPV infection is a viral infection of the epithelial tissue and, in addition to genital warts, HPV infection can lead to a variety of cancers. Among them, persistent infection with high-risk human papillomavirus (HPV) is the main cause of cervical cancer. Additionally, HPV infection is also associated with several types of cancers, such as anal cancer, head and neck cancer, and oropharyngeal cancer in both men and women [3-5]. Some studies have shown that HPV infection causes $60-70 \%$ of 
oropharyngeal squamous cell carcinomas (OPSCCs) [6]. In 2020 alone, China reported 109,741 new cervical cancer cases and 59,060 deaths, corresponding to $18.2 \%$ of diagnoses and $17.3 \%$ of deaths from cervical cancer worldwide [7], making it the most common cancer of the female reproductive system in China [8]. Men are also at risk for other HPV-related cancers including penile, anal, and oral cancers [9]. Worldwide, HPV infection has posed a significant health threat and disease burden.

Vaccines have been one of the most effective interventions for infectious diseases [10]. The introduction of HPV vaccines in many countries has resulted in a substantial reduction in the prevalence of specific HPV infection, and a recent meta-analysis that included 60 million people showed that HPV vaccination had a substantial impact on the incidence of HPV infection and related diseases [11]. The GlaxoSmithKline 2vHPV vaccine was introduced in mainland China in August 2016, with the 4vHPV vaccine and 9vHPV vaccine being launched in 2017 and 2018, respectively. However, the HPV vaccine is a self-pay vaccine which has not yet been included in China's national immunization program. The 4vHPV (RMB 798/shot) cost is slightly higher than the 2vHPV (RMB 580/shot). The latest $9 \mathrm{vHPV}$ (RMB 1298/shot) is nearly double the price of the 4vHPV. A recent survey showed that only about $3 \%$ of women and $1 \%$ of men in mainland China have received the HPV vaccine [12], which is clearly a very low rate.

There is now growing evidence that sexually transmitted infections among college students are on the rise and that the college student population is bearing a high burden of sexually transmitted infections. It is clear that they are in the high-risk age group for HPV infection [13-15]. In mainland China, the government has not approved HPV vaccination for men, and the risks posed by HPV infection to men have not been given sufficient attention. Most studies on HPV and HPV vaccination attitudes in China currently focus only on women, and few studies have analyzed both male and female knowledge of HPV and HPV vaccine. In addition, college students are at an age where they are able to process new knowledge and decide on whether to receive HPV vaccination independently [16]. Their perceptions, attitudes, and behaviors regarding HPV vaccination are important for their health.

The main objective of this study was therefore to understand the current state of knowledge about HPV and HPV vaccine among male and female college students and the factors that influence vaccination intentions, and to compare the differences between the genders. We hope to provide a scientific basis for policy formulation to improve HPV vaccination rates among college students.

\section{Materials and Methods}

\subsection{Study Participants}

We conducted this cross-sectional study in August 2020 in Wenzhou university town, which has the highest concentration of college students in Wenzhou, with five universities in the region. We calculated the sample size based on the following formula:

$$
n=\frac{z_{\alpha / 2}^{2} \times p(1-p)}{d^{2}}
$$

where $d$ is the permissible error and takes the value of $d=0.04 \times p . p$ is the estimated HPV acceptance rate and based on previous studies [17], we determined that $p$ was $73 \%$, taking into account issues such as invalid questionnaires and increasing the sample size by $10 \%$, the final sample size was at least 977 . Due to the COVID-19 epidemic, face-to-face investigations were restricted. We generated a link to the online questionnaire via the survey platform (https:/ / www.wjx.cn, accessed on 8 July 2021), then posted the survey link and respondents completed the questionnaire online. We first randomly selected three universities within the university town and then recruited students by convenience sampling. Participants were required to fill in the questionnaire and submit it within a limited period of time. Participants in this study included both males and females. The inclusion criteria were: (1) college students; (2) Chinese citizens, and (3) Chinese reading 
ability. Participants were informed of the purpose and content of the survey and informed consent was obtained prior to completion. To prevent response bias, participants were guaranteed anonymity and their personal information was kept strictly confidential. In addition, participants received no compensation for their cooperation.

\subsection{Instruments}

Through a review of relevant literature and expert discussion, we designed a questionnaire consisting of four sections, including demographic information, knowledge of HPV infection, knowledge of HPV vaccine and attitudes towards HPV vaccination and reasons for it. In order to quantify the level of knowledge of HPV-related knowledge and HPV vaccine knowledge among college students, we assigned scores to the questions on HPV infection knowledge and vaccine knowledge on the questionnaire, where each question was scored out of 3 or 5 points, with correct answers scored and incorrect answers not scored, out of a total of 55 points. In total, 16 questions were scored out of 44 points for HPV-related knowledge and 4 questions out of 11 points for HPV vaccine knowledge. Details of the questionnaire are attached.

\subsection{Statistical Analysis}

Participants' demographic characteristics, knowledge of HPV and HPV vaccine, access to knowledge, attitudes to vaccination and related factors were expressed as frequencies and percentages. HPV infection knowledge scores and HPV vaccine knowledge scores were expressed as mean \pm standard deviation. Differences between groups were compared by $t$-test and chi-square test, stratified by gender. Attitude towards HPV vaccination was used as the dependent variable, which was categorized as "yes" and "no", and a multivariable logistic regression analysis was conducted to identify the influencing factors related to the attitude towards HPV vaccination among male and female college students. Statistical significance was assessed by two-tailed tests with $\alpha$ level of 0.05 .

\section{Results}

\subsection{Demographic Characteristics of all Participants}

A total of 1035 questionnaires were returned in the end, after excluding 33 invalid questionnaires due to incomplete responses, 1002 questionnaires were included in the final analysis. The demographic characteristics of the study participants are shown in Table 1. The mean age of the participants was $20.52 \pm 1.76$ years, with 374 males $(37.3 \%)$ and 628 females (62.7\%). Of these, 43 (4.3\%) were enrolled in a master's degree and higher, 617 $(61.6 \%)$ were medical professionals, and $215(21.5 \%)$ were other members of the household in medical-related occupations.

\subsection{Knowledge of HPV and HPV Vaccine}

In the study, $90.2 \%$ and $69.2 \%$ of college students had heard of HPV and HPV vaccine respectively. The percentage of males who had heard of HPV and HPV vaccine was $85.3 \%$ and $53.7 \%$, respectively, compared to $93.2 \%$ and $78.3 \%$ of females. The difference was statistically significant $(p<0.001)$. Among college students who had heard of HPV, both males and females mostly learned about HPV through the internet, with $69.4 \%$ and $81.6 \%$ of college students choosing this option, respectively. Among all college students, the two most desired ways for males and females to learn about HPV were the same: the internet $(61.0 \%$ vs. $75.6 \%)$ and school lectures $(60.7 \%$ vs. $69.3 \%)$, as shown in Tables S1 and S2.

Table 2 demonstrates the knowledge of college students about HPV and HPV vaccine. College students scored $22.73 \pm 9.01$ (44 points) and $5.06 \pm 3.03$ (11 points) for HPV-related knowledge and HPV vaccine knowledge, respectively. In terms of HPV-related knowledge, males and females scored $21.05 \pm 9.47$ and $23.74 \pm 8.58$, respectively, with males scoring lower than females and the difference being statistically significant $(p<0.001)$. Specifically, females were more likely than males to know the transmission route of HPV, with a statistically significant difference $(p=0.001)$. As for other questions regarding knowledge 
of high-risk HPV and HPV-related disease treatment, the scores of males were lower than those of females, with statistically significant differences. In terms of HPV vaccine knowledge, only when asked: "Are you aware of the current status of the HPV vaccine for men today?", males scored higher than females, with a statistically significant difference $(p=0.01)$. The rest of the HPV vaccine questions were answered better by women than men, with a statistically significant difference.

Table 1. Demographic characteristics of study participants $(n=1002)$.

\begin{tabular}{ccc}
\hline Characteristics & Frequency $(n)$ & Percent (\%) \\
\hline Gender & 628 & \\
Female & 374 & 62.7 \\
Male & & 37.3 \\
Age (years) & 223 & 22.3 \\
$<20$ years & 686 & 68.5 \\
20-23 years & 93 & 9.3 \\
$\geq 23$ years & & \\
Reading record of formal & 959 & 95.7 \\
schooling & 43 & 4.3 \\
Bachelor's degree & & \\
Master's degree and higher & 385 & 38.4 \\
Major & 617 & 61.6 \\
Non-medical & & \\
Medical & 787 & 78.5 \\
Family members engaged in & 215 & 21.5 \\
medical related occupations & & \\
No & & \\
\hline
\end{tabular}

Table 2. College students' knowledge (based on scores) of HPV (out of 44 points) and HPV vaccination (out of 11 points).

\begin{tabular}{|c|c|c|c|c|c|}
\hline & Questions (Points) & Total & Female & Male & $p$ \\
\hline \multirow{14}{*}{$\begin{array}{l}\text { HPV-related } \\
\text { knowledge }\end{array}$} & Do you know that men can also be infected with HPV? (3) & $1.23 \pm 0.86$ & $1.24 \pm 0.82$ & $1.23 \pm 0.93$ & 0.842 \\
\hline & What are the ways of transmission of HPV do you know? (3) & $1.52 \pm 1.11$ & $1.61 \pm 1.09$ & $1.36 \pm 1.13$ & 0.001 \\
\hline & $\begin{array}{c}\text { Do you think men and women with HPV infection need to be } \\
\text { treated? (3) }\end{array}$ & $2.97 \pm 0.22$ & $2.97 \pm 0.22$ & $2.97 \pm 0.21$ & 0.987 \\
\hline & $\begin{array}{l}\text { Which of the following diseases do you think are associated with } \\
\text { HPV infection? (5) }\end{array}$ & $2.89 \pm 1.47$ & $3.09 \pm 1.41$ & $2.57 \pm 1.51$ & 0.000 \\
\hline & $\begin{array}{l}\text { Which of the following male diseases do you think are caused by } \\
\qquad \text { HPV? (3) }\end{array}$ & $0.99 \pm 0.99$ & $1.01 \pm 0.99$ & $0.95 \pm 0.99$ & 0.396 \\
\hline & $\begin{array}{l}\text { What do you think is the difference between high-risk HPV and } \\
\text { low-risk HPV? (3) }\end{array}$ & $2.00 \pm 1.42$ & $2.14 \pm 1.36$ & $1.76 \pm 1.48$ & 0.000 \\
\hline & Which diseases do you think are caused by high-risk HPV? (4) & $1.72 \pm 1.51$ & $1.84 \pm 1.51$ & $1.51 \pm 1.49$ & 0.001 \\
\hline & Do you know anything about transient HPV infection? (3) & $1.01 \pm 0.88$ & $1.04 \pm 0.87$ & $0.97 \pm 0.92$ & 0.208 \\
\hline & Do you know about the self-limiting nature of HPV? (3) & $1.09 \pm 0.93$ & $1.10 \pm 0.91$ & $1.08 \pm 0.97$ & 0.798 \\
\hline & Do you think there is cross infection between sexual partners? (3) & $2.21 \pm 1.32$ & $2.35 \pm 1.24$ & $1.97 \pm 1.43$ & 0.000 \\
\hline & Do you know the basis for the diagnosis of HPV? (3) & $0.66 \pm 1.24$ & $0.71 \pm 1.28$ & $0.56 \pm 1.17$ & 0.058 \\
\hline & Do you think men with HPV infection can be cured? (3) & $2.11 \pm 1.37$ & $2.16 \pm 1.35$ & $2.03 \pm 1.41$ & 0.151 \\
\hline & $\begin{array}{l}\text { Which of the following treatments do you consider to be } \\
\text { effective? (5) }\end{array}$ & $2.34 \pm 1.88$ & $2.49 \pm 1.91$ & $2.10 \pm 1.81$ & 0.001 \\
\hline & Total $(44)$ & $22.73 \pm 9.01$ & $23.74 \pm 8.58$ & $21.05 \pm 9.47$ & 0.000 \\
\hline \multirow{5}{*}{$\begin{array}{l}\text { HPV vaccine } \\
\text { knowledge }\end{array}$} & $\begin{array}{l}\text { Which group of people do you think should be vaccinated against } \\
\text { HPV? (3) }\end{array}$ & $1.25 \pm 1.48$ & $1.52 \pm 1.50$ & $0.79 \pm 1.32$ & 0.000 \\
\hline & $\begin{array}{c}\text { Do you know the current status of the HPV vaccine for men } \\
\text { today? (3) }\end{array}$ & $0.56 \pm 1.17$ & $0.49 \pm 1.11$ & $0.69 \pm 1.26$ & 0.010 \\
\hline & What do you think is the best time to get HPV vaccination? (3) & $2.01 \pm 1.41$ & $2.22 \pm 1.32$ & $1.65 \pm 1.49$ & 0.000 \\
\hline & $\begin{array}{l}\text { Which of the following diseases do you think HPV vaccination can } \\
\text { prevent? (2) }\end{array}$ & $1.24 \pm 0.90$ & $1.33 \pm 0.88$ & $1.09 \pm 0.92$ & 0.000 \\
\hline & Total $(11)$ & $5.06 \pm 3.03$ & $5.56 \pm 2.89$ & $4.22 \pm 3.07$ & 0.000 \\
\hline
\end{tabular}




\subsection{HPV Vaccination Intention}

Figure 1 depicts the attitudes of college students towards HPV vaccination, with 714 (71.3\%) of them willing to receive HPV vaccination. There was a significant difference between male and female willingness to receive HPV vaccination $(55.9 \%$ vs. $80.4 \%, p<0.001)$. Figure 2 depicts facilitators of and barriers to HPV vaccination acceptance. Among the factors that promoted HPV vaccination, the top three most selected by females were "Fear of HPV infection" (84.0\%), "Fear of HPV-related disease" (73.1\%), and "Benefit the partner" $(35.2 \%)$. For males, it was "Fear of HPV-related disease" (41.2\%), "Benefit the partner" (38.2\%), "Fear of HPV infection" (37.6\%). When choosing the factors that prevented them from getting the HPV vaccine, "Concern about vaccine efficacy and safety" was the biggest barrier for males (49.6\%), with nearly half of those who did not want to get the HPV vaccine choosing this option. Males cited "HPV vaccines are expensive" as the most important barrier to getting the HPV vaccine (72.7\%). When asked "Which of the followings is most likely to prompt your own vaccination?", 73.4\% of females chose "Vaccine price reduced to acceptable range", unlike females, "Doctor's advice" was the most frequently chosen option by males $(57.0 \%)$, as shown in Table S3.

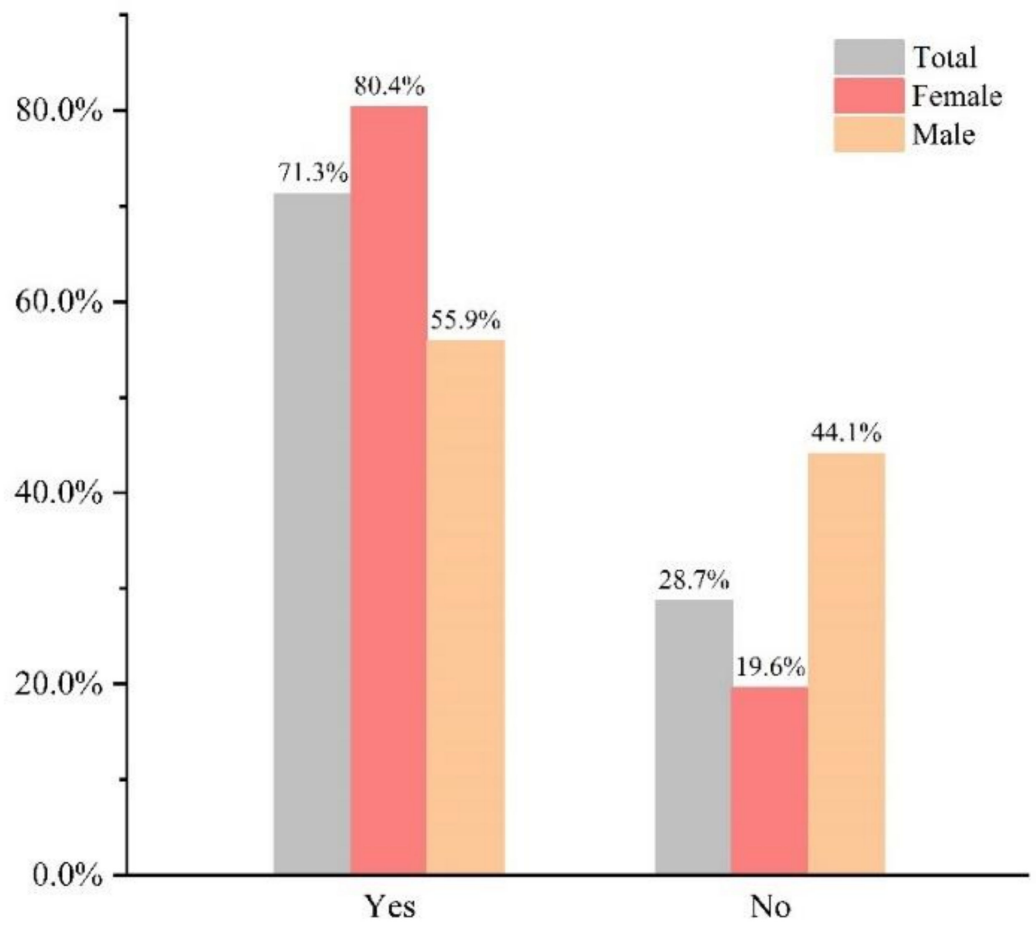

Figure 1. Willingness to vaccinate against HPV. Note: "Yes": participants were willing to be vaccinated against HPV; “No": participants were unwilling to be vaccinated against HPV.

\subsection{Factors Associated with the Willingness to Receive HPV Vaccination}

A multivariate logistic regression analysis of the factors associated with college students' willingness to receive HPV vaccination are shown in Table 3 . The male gender $(\mathrm{aOR}=0.388,95 \%$ CI $0.287-0.527)$ was a significant predictor of reluctance to receive HPV vaccine, while higher HPV infection knowledge score (aOR = 1.706, 95\% CI: 1.225-2.378) and higher HPV vaccine knowledge score (aOR = 2.329, 95\% CI: 1.644-3.299) were significant predictors of willingness to receive HPV vaccine. Analysis stratified by gender showed different results for males and females. Having heard of the HPV vaccine and a higher HPV vaccine knowledge score $(\mathrm{aOR}=3.486,95 \% \mathrm{CI}: 2.122-5.729)$ were significant predictors of willingness to receive the HPV vaccine among female college students, whereas high willingness among males was only associated with a higher HPV-related knowledge score $(\mathrm{aOR}=1.868,95 \% \mathrm{CI}: 1.154-3.022)$, as shown in Table 4 . 


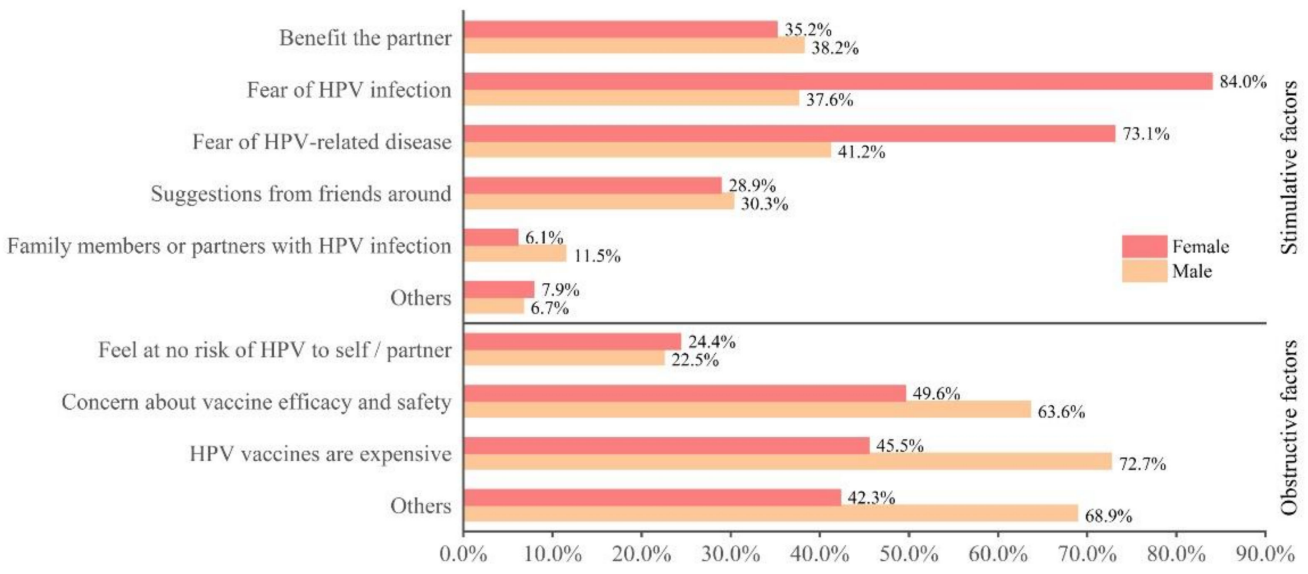

Figure 2. Self-reported facilitators of and barriers to HPV vaccination acceptance. Note: Only participants willing to be vaccinated with HPV answered the question "What are the reasons why you are willing to get HPV vaccination? (multiple choice)" $(n=714)$; only participants who were unwilling to vaccinate with HPV answered the question "What are the reasons that influence you to get HPV vaccination? (multiple choice)" $(n=288)$.

Table 3. Factors associated with the willingness to receive HPV vaccination.

\begin{tabular}{|c|c|c|}
\hline Variable & OR $(95 \% \mathrm{CI})$ & aOR $(95 \% \mathrm{CI})$ \\
\hline \multicolumn{3}{|l|}{ Gender } \\
\hline Female & ref & ref \\
\hline Male & $0.309(0.232-0.410) * * *$ & $0.388(0.287-0.527)^{* * *}$ \\
\hline \multicolumn{3}{|l|}{ Reading record of formal schooling } \\
\hline Bachelor's degree & ref & ref \\
\hline Master's degree and higher & $2.131(0.937-4.847)$ & $2.513(0.866-5.353)$ \\
\hline \multicolumn{3}{|l|}{ Major } \\
\hline Non-medical & ref & ref \\
\hline Medical & $1.312(0.993-1.734)$ & $0.983(0.707-1.368)$ \\
\hline \multicolumn{3}{|l|}{$\begin{array}{l}\text { Family members engaged in } \\
\text { medical related occupations }\end{array}$} \\
\hline No & ref & ref \\
\hline Yes & $1.343(0.949-1.900)$ & $1.354(0.927-1.976)$ \\
\hline \multicolumn{3}{|l|}{ Heard of HPV } \\
\hline No & ref & ref \\
\hline Yes & $3.514(2.297-5.375) * * *$ & $1.533(0.932-2.524)$ \\
\hline \multicolumn{3}{|l|}{ Heard of the HPV vaccine } \\
\hline No & ref & ref \\
\hline Yes & $3.186(2.387-4.252) * * *$ & $1.397(0.972-2.008)$ \\
\hline \multicolumn{3}{|l|}{ HPV infection knowledge score } \\
\hline Low $(\leq 22)$ & ref & ref \\
\hline High $(>22)$ & $2.615(1.971-3.469) * * *$ & $1.706(1.225-2.378) * *$ \\
\hline \multicolumn{3}{|l|}{ HPV vaccine knowledge score } \\
\hline Low $(\leq 5)$ & ref & ref \\
\hline $\operatorname{High}(>5)$ & $3.612(2.634-4.952) * * *$ & $2.329(1.644-3.299)^{* * *}$ \\
\hline
\end{tabular}

Note: Variables in univariate logistic regression models eventually entered the multivariable logistic regression model. HPV, human papillomavirus; OR, odds ratio; aOR, adjusted odds ratio; CI, confidence interval. "**" indicates $p<0.01, “ * * * *$ indicates $p<0.001$. 
Table 4. Factors associated with the willingness to receive HPV vaccination by gender.

\begin{tabular}{|c|c|c|c|c|}
\hline \multirow{2}{*}{ Variable } & \multicolumn{2}{|c|}{ Female } & \multicolumn{2}{|c|}{ Male } \\
\hline & OR $(95 \%$ CI $)$ & aOR $(95 \% \mathrm{CI})$ & OR $(95 \%$ CI $)$ & aOR $(95 \% \mathrm{CI})$ \\
\hline \multicolumn{5}{|l|}{ Reading record of formal schooling } \\
\hline Bachelor's degree & ref & ref & ref & ref \\
\hline Master's degree and higher & $3.284(0.769-14.027)$ & $2.683(0.571-12.617)$ & $1.608(0.539-4.800)$ & $1.960(0.610-6.303)$ \\
\hline \multicolumn{5}{|l|}{ Major } \\
\hline Non-medical & ref & ref & ref & ref \\
\hline Medical & $1.236(0.827-1.847)$ & $1.037(0.657-1.637)$ & $1.360(0.897-2.063)$ & $1.046(0.644-1.700)$ \\
\hline \multicolumn{5}{|c|}{$\begin{array}{l}\text { Family members engaged in medical } \\
\text { related occupations }\end{array}$} \\
\hline No & ref & ref & ref & ref \\
\hline Yes & $1.220(0.734-2.028)$ & $1.224(0.705-2.124)$ & $1.687(1.024-2.780) *$ & $1.603(0.956-2.688)$ \\
\hline \multicolumn{5}{|l|}{ Heard of HPV } \\
\hline No & ref & ref & ref & ref \\
\hline Yes & $5.020(2.660-9.475) * * *$ & $1.560(0.736-3.309)$ & $1.946(1.089-3.476) *$ & $1.364(0.714-2.607)$ \\
\hline \multicolumn{5}{|l|}{ Heard of the HPV vaccine } \\
\hline No & ref & ref & ref & ref \\
\hline Yes & $4.440(2.895-6.811)^{* * *}$ & $2.269(1.353-3.805) * *$ & $1.527(1.012-2.303)$ * & $0.927(0.557-1.542)$ \\
\hline \multicolumn{5}{|l|}{ HPV infection knowledge score } \\
\hline Low $(\leq 22)$ & ref & ref & ref & ref \\
\hline $\operatorname{High}(>22)$ & $2.590(1.730-3.878) * * *$ & $1.574(0.983-2.522)$ & $2.188(1.437-3.331)^{* * *}$ & $1.868(1.154-3.022)$ * \\
\hline \multicolumn{5}{|l|}{ HPV vaccine knowledge score } \\
\hline Low $(\leq 5)$ & ref & ref & ref & ref \\
\hline $\operatorname{High}(>5)$ & $4.917(3.064-7.891) * * *$ & $3.486(2.122-5.729)$ * & $1.990(1.259-3.146) * *$ & $1.520(0.901-2.565)$ \\
\hline
\end{tabular}

Note: Variables in univariate logistic regression models eventually entered the multivariable logistic regression model. HPV, human papillomavirus; OR, odds ratio; aOR, adjusted odds ratio; CI, confidence interval. "*" indicates $p<0.05$, " "**" indicates $p<0.01$, "***" indicates $p<0.001$.

\section{Discussion}

In this study, we found that the knowledge of HPV and HPV vaccine among college students in Wenzhou was at a medium to low level, even though awareness of HPV and HPV vaccine was high. The overall knowledge level of males is lower than that of females. In addition, for male college students, providing more knowledge about HPV infection is helpful to promote their willingness to vaccinate. The main findings of this study may help to provide effective educational guidance and interventions for improving the vaccination rate of the target population in the future.

The HPV vaccine does not prevent people who are already infected with HPV from developing cervical cancer, so the highest efficacy of the HPV vaccine is when it is administered before sexual debut. In fact, many Western countries have school-based vaccination programs for 12-13 years old boys and girls [18]. In the UK, the NHS vaccination program to prevent cervical cancer has so far stopped thousands of women from developing the disease and experiencing pre-cancerous changes to cells [19]. However, we believe that it is valuable to investigate HPV vaccination among Chinese college students. Influenced by traditional Chinese culture, Chinese college students are relatively conservative in their thinking, the situation of college student sexual behavior in China is different from that in Europe. In Guangzhou, a developed city in China, a survey of college students showed that a majority (85.2\%) of students claimed that they had never engaged in sexual activity [20], while a Greek survey of adolescents aged 15-21 found that $48.0 \%$ of students answered that they had been sexually active [21]. Furthermore, college students not only fall in the age group at high risk for HPV infection but also in childbearing age, the decision to receive the vaccine or not has an impact on their risk of acquiring HPV, which can also be passed on to the next generation if HPV is present during delivery. Moreover, according to a metaanalysis in 2019 [11], HPV-related endpoints such as HPV16, HPV18, anogenital warts, and cervical intraepithelial neoplasia grade $2+(\mathrm{CIN} 2+)$ decreased significantly among women aged 20-24 years following HPV vaccination. For the above reasons, it is very meaningful to promote HPV vaccination among Chinese college students.

Since the development of the HPV vaccine, numerous research articles have appeared in China on the knowledge, attitudes, and behavioral tendencies of college students [22]. 
According to the survey results, the awareness of HPV and HPV vaccine was higher among college students in the current study compared to previous studies of Chinese college students. In a 2013 study, only $10.3 \%$ and $5.4 \%$ of college students had heard of HPV and HPV vaccine, respectively [23], and in a 2014 survey of Chinese college students' awareness of HPV and HPV vaccine, the figures were only 14.3\% and 8.1\% [24]. After the HPV vaccine was approved in China in 2016, Chinese college students began to gradually become aware of HPV and HPV vaccine. A survey in Changsha in 2017 showed that the awareness rate of college students about HPV vaccine was 32.4\% [25] and a study conducted in Beijing in 2018 found that the awareness rate of college students about HPV and HPV vaccine was 76.5\% and $72.6 \%$, respectively [26]. The increased publicity by the authorities in recent years and the widespread availability of HPV vaccination in China may explain the high awareness of HPV and HPV vaccine in this study. In addition, as the majority of participants had a medical background, that may have contributed to higher knowledge on HPV. Medical students were reported to be more likely to have heard of HPV and to have a higher level of knowledge than non-medical students [27].

From the results of this study, the scores of college students' knowledge of HPV and HPV vaccine were $22.73 \pm 9.01$ (44 points) and $5.06 \pm 3.03$ (11 points), respectively, which are at a low to moderate level, indicating that although the awareness rate has increased, college students' knowledge of HPV and HPV vaccine is still low. In our study population, a large proportion of college students, both males and females, were unaware that HPV can infect men, and that more education intervention targeted at men is needed. In answering the question on HPV and diseases associated with high-risk HPV infection, males performed worse than females, although both scores were low, indicating to some extent the lack of knowledge of HPV infection among college students, especially among male students. The fact that the HPV vaccine is not approved for use in males in mainland China and that HPV infection is mainly associated with cervical cancer in females has contributed to this phenomenon. In a survey conducted in 2015, there was a need to improve the education of young males about HPV infection, its associated diseases, and the benefits of the vaccination [26]. Furthermore, the results showed that college students of both sexes were not very clear about the basis of diagnosis of HPV infection, which may delay early consultation of those with suspected infection. When asked about HPV vaccine-related issues, females in general showed a higher level of knowledge than males, and females were more aware than males of the period of HPV vaccination and the benefits of the vaccination, in line with the findings of some previous national and international studies [27-29]. We found that the internet was the most important source of information for college students, both males and females, who were aware of HPV. In addition, the internet and popular science lectures were the most chosen avenues of expectation for all to learn about HPV, which is similar to the results of international studies [30,31]. Healthcare providers have been shown to play a pivotal role in promoting vaccination in different settings and other risk groups [32], and schools should strengthen their collaboration with health care providers, which may be an effective measure to increase HPV knowledge among college students.

Proportion of college students with the intention to vaccinate in several studies in China ranged from 33 to $70 \%[20,23,24,33]$. When the HPV vaccine was not yet available in mainland China, studies in 2012 and 2013 showed a high intention to vaccinate among college students at $70 \%$ and $70.6 \%$, respectively $[23,24]$. However, in the two studies in 2018 and 2019 , this figure was only $44.4 \%$ and $33.7 \%$, respectively [20,33]. This may be due to the vaccine scandal that took place in China in 2018, when a large number of substandard vaccines reached the market. A study demonstrated that public confidence was significantly affected by the vaccine scandal, particularly for vaccine producers and drug regulators [34]. In contrast, the higher vaccination intention in this study may be due to the fact that Wenzhou is located in the eastern region of China, and a recent study showed that college students in the eastern region of mainland China are more willing to get the HPV vaccine compared to the western region [35]. In addition to this, the COVID-19 
pandemic in the first half of 2020 has promoted concern for people's own health, and the results of several studies have shown that people's fear of COVID-19 may promote preventive health behaviors, thus acting as a form of protection [36,37].

In exploring factors influencing attitudes towards HPV vaccination, our findings were similar to those of some other studies [24,33]. The findings of the study suggest that fear of HPV infection and the perceived benefits to be gained from HPV vaccination were facilitators of HPV vaccination among college students. At the same time, the lack of information about HPV vaccination, as well as concerns about side effects and potential safety issues, discouraged college students from receiving the HPV vaccine, a finding that is consistent with national and international studies [27,38]. Male college students were more concerned about the price of the HPV vaccine. In addition, the lower price of the HPV vaccine was also an important facilitator of HPV vaccination among female college students. In mainland China, medical insurance does not cover the HPV vaccine and requires individuals to pay for the vaccination, which costs between RMB 1800 and 4000 for three shots. Although differences in perceptions of the cost of vaccination may be related to socioeconomic status, this may be an important factor in deciding whether or not to receive HPV vaccine [33]. In addition to providing HPV knowledge, doctors can also affect college students' HPV vaccination attitude. Logistic regression results show that gender differences influence willingness to receive the vaccine, and we found that female college students who had heard of the HPV vaccine had a higher willingness to receive the vaccine, while there was no effect for males, possibly because the term "cervical cancer vaccine" is often used in the marketing of the HPV vaccine, one might assume that it is not relevant to men. More specifically, the higher level of HPV vaccine knowledge among female college students was an important contributing factor to their HPV vaccination, while male participants' knowledge about HPV infection may have had a greater impact on them. This result suggests that targeted assistance could be provided to both male and female college students, focusing on the role and knowledge of the HPV vaccine for female students, and more knowledge about HPV infection for males, in order to improve overall $\mathrm{HPV}$ vaccination rates among college students.

Studies in several countries have shown that extending the current HPV vaccination program to the male population is a highly cost-effective preventive intervention that can better prevent diseases such as anogenital cancer, a proportion of head and neck cancer, cancer precursors, and genital warts in both men and women [39,40]. High HPV vaccine coverage in both sexes would help achieve herd immunity and largely reduce HPV, but it is currently difficult to include the HPV vaccine in China's national immunization program. China is still a developing country with a large population. In addition, China is not a GAVI (The Global Alliance for Vaccines and Immunization) supported country and thus may not receive extensive financial assistance to maintain the HPV vaccine supply [20]. However, the Chinese government is accelerating free HPV vaccination and actively seeking cooperation with organizations such as GAVI. From 2020, some cities in China have already started to gradually introduce free HPV vaccination among girls of school age, exploring suitable experiences for the promotion of free HPV vaccination. Given China's vast geography and significant regional differences in economic development and disease burden [41], we believe it is challenging to address the issue of free HPV vaccination in China with one model, and we need to actively explore more different models to promote free HPV vaccination in China. The first Chinese domestic HPV vaccine against HPV 16 and 18 (Cecolin, Innovax, Xiamen, China) was licensed by the Chinese Food and Drug Administration on 31 December 2019 and approved for a two-dose schedule for girls aged 9-14 years. The new vaccine Cecolin is priced at RMB 329 per dose (about half of the price of Cervarix) and has similar efficacy to Cervarix, providing an unprecedented opportunity for China [42].

It is necessary for government and universities to take targeted measures such as establish a national financial subsidy, increasing health education related to HPV infection in the school curriculum, and promoting knowledge about HPV and HPV vaccine through 
the internet and social media. Vaccine health education and the development of healthy behaviors among college students depend not only on the support of the government, medical institutions, and schools, but also on the increased awareness of college students to prevent HPV infection. Only by recognizing the seriousness and consequences of HPV infection and the effectiveness of the HPV vaccine can the overall HPV vaccination rate among college students be increased.

There are several limitations to this study. Firstly, this study used self-reported data collected using a questionnaire and may be subject to self-report bias and recall bias. Secondly, due to the cross-sectional nature of the study, strong causal relationships cannot be provided and caution should be exercised in interpreting the influences. Finally, as the majority of college students in this study had medical backgrounds, the study population was limited in its representativeness.

\section{Conclusions}

This study shows that college students of both sexes in Wenzhou have a medium level of willingness to accept HPV vaccine, a medium to low level of knowledge about HPV and HPV vaccine, and a lower overall level of knowledge among males than females. The low level of knowledge about HPV and HPV vaccine and the high price of the vaccine are the main barriers to HPV vaccination among college students. For male college students, providing more knowledge about HPV infection is helpful to promote their willingness to vaccinate. Strengthening health education on HPV-related knowledge and lowering the price of the vaccine would help promote the HPV vaccine among the college student population.

Supplementary Materials: The following are available online at https://www.mdpi.com/article/10 .3390 /vaccines10010010/s1, Table S1: Manners to HPV understanding $(n=904)$, Table S2: Desired manners to gain further insight into HPV $(n=1002)$, Table S3: Self-perceived factors that promote HPV vaccination $(n=1002)$.

Author Contributions: All authors have substantially contributed to the submitted work. G.C., B.W., X.D., H.H., Y.L., K.M. and Z.W. were involved in study conception and design; G.C., B.W., X.D., M.Z. and Y.L. performed the study and participated in data collection; G.C., B.W., X.D., K.M. and Z.W. were involved in data analysis and interpretation. G.C. and Z.W. wrote the manuscript. All authors reviewed and edited the manuscript and approved its submission. All authors have read and agreed to the published version of the manuscript.

Funding: This work was supported by General Research Project of Zhejiang Provincial Education Department (Y202146906); Research Project of Wenzhou Medical University (KJHX2014).

Institutional Review Board Statement: The study was conducted according to the guidelines of the Declaration of Helsinki, and approved by the Institutional Review Board of Wenzhou Medical University (2021023).

Informed Consent Statement: Informed consent was obtained from all subjects involved in the study.

Data Availability Statement: The data that support the findings of this study is available, you can request the data directly from the authors. E-mail: andrologywzg@wmu.edu.cn.

Acknowledgments: We would like to thank all the college students who participated in this study.

Conflicts of Interest: The authors declare no conflict of interest.

\section{References}

1. Schiffman, M.; Castle, P.E.; Jeronimo, J.; Rodriguez, A.C.; Wacholder, S. Human papillomavirus and cervical cancer. Lancet 2007, 370, 890-907. [CrossRef]

2. Bloem, P.; Ogbuanu, I. Vaccination to prevent human papillomavirus infections: From promise to practice. PLoS Med. 2017, 14, e1002325. [CrossRef] [PubMed]

3. Mccormack, P.L. Quadrivalent Human Papillomavirus (Types 6, 11, 16, 18) Recombinant Vaccine (Gardasil((R))): A Review of Its Use in the Prevention of Premalignant Anogenital Lesions, Cervical and Anal Cancers, and Genital Warts. Drugs 2014, 74, 1253-1283. [CrossRef] [PubMed] 
4. Herrero, R.; Gonzalez, P.; Markowitz, L.E. Present status of human papillomavirus vaccine development and implementation. Lancet Oncol. 2015, 16, E206-E216. [CrossRef]

5. Serrano, B.; Brotons, M.; Bosch, F.X.; Bruni, L. Epidemiology and burden of HPV-related disease. Best Pract. Res. Clin. Obstet. Gynaecol. 2018, 47, 14-26. [CrossRef] [PubMed]

6. Westra, W.H. The changing face of head and neck cancer in the 21st century: The impact of HPV on the epidemiology and pathology of oral cancer. Head Neck Pathol. 2009, 3, 78-81. [CrossRef] [PubMed]

7. Bruni, L.; Albero, G.; Serrano, B.; Mena, M.; Collado, J.J.; Gómez, D.; Muñoz, J.; Bosch, F.X.; de Sanjosé, S. ICO/IARC Information Centre on HPV and Cancer (HPV Information Centre). Human Papillomavirus and Related Diseases in China. Summary Report 22 October 2021. Available online: https:/ / hpvcentre.net/statistics/reports/CHN.pdf?t=1639116428387 (accessed on 13 December 2021).

8. Pan, X.; Li, R.; Pan, A.; Larson, H. Human papillomavirus vaccine approval in China: A major step forward but challenges ahead Lancet Infect. Dis. 2016, 16, 1322-1323. [CrossRef]

9. Moscicki, A.B.; Palefsky, J.M. Human Papillomavirus in Men: An Update. J. Low. Genit. Tract Dis. 2011, 15, 231-234. [CrossRef]

10. Levine, O.S.; Bloom, D.E.; Cherian, T.; de Quadros, C.; Sow, S.; Wecker, J.; Duclos, P.; Greenwood, B. New Decade of Vaccines 4 The future of immunisation policy, implementation, and financing. Lancet 2011, 378, 439-448. [CrossRef]

11. Drolet, M.; Benard, E.; Perez, N.; Brisson, M.; Boily, M.C.; Ali, H.; Baldo, V.; Brassard, P.; Brotherton, J.M.L.; Callander, D.; et al Population-level impact and herd effects following the introduction of human papillomavirus vaccination programmes: Updated systematic review and meta-analysis. Lancet 2019, 394, 497-509. [CrossRef]

12. Hu, S.; Xu, X.; Zhang, Y.; Liu, Y.; Yang, C.; Wang, Y.; Wang, Y.; Yu, Y.; Hong, Y.; Zhang, X.; et al. A nationwide post-marketing survey of knowledge, attitude and practice toward human papillomavirus vaccine in general population: Implications for vaccine roll-out in mainland China. Vaccine 2021, 39, 35-44. [CrossRef]

13. Zheng, N.; Guo, Y.; Padmadas, S.; Wang, B.; Wu, Z. The increase of sexually transmitted infections calls for simultaneous preventive intervention for more effectively containing HIV epidemics in China. BJOG 2014, 121, 35-44. [CrossRef]

14. Ehrsson, Y.T.; Stenhammar, C.; Rosenblad, A.; Akerud, H.; Larsson, M.; Tyden, T. Self-reported sexually transmitted infections among female university students. Upsala J. Med Sci. 2016, 121, 45-49. [CrossRef]

15. Haghir, E.; Madampage, C.; Mahmood, R.; Moraros, J. Risk Factors Associated with Self-reported Sexually Transmitted Infections among Postsecondary Students in Canada. Int. J. Prev. Med. 2018, 9, 49.

16. Rohde, R.L.; Boakye, E.A.; Christopher, K.M.; Geneus, C.J.; Walker, R.J.; Varvares, M.A.; Osazuwa-Peters, N. Assessing university students' sexual risk behaviors as predictors of human papillomavirus (HPV) vaccine uptake behavior. Vaccine 2018, 36, 3629-3634. [CrossRef]

17. Fu, C.; Pan, X.; Zhao, Z.; Saheb-Kashaf, M.; Chen, F.; Wen, Y.; Yang, C.; Zhong, X. Knowledge, Perceptions and Acceptability of HPV Vaccination among Medical Students in Chongqing, China. Asian Pac. J. Cancer Prev. 2014, 15, 6187-6193. [CrossRef]

18. Bjerke, R.D.; Laake, I.; Feiring, B.; Aamodt, G.; Trogstad, L. Time trends in HPV vaccination according to country background: A nationwide register-based study among girls in Norway. BMC Public Health 2021, 21, 854. [CrossRef]

19. Falcaro, M.; Castano, A.; Ndlela, B.; Checchi, M.; Soldan, K.; Lopez-Bernal, J.; Elliss-Brookes, L.; Sasieni, P. The effects of the national HPV vaccination programme in England, UK, on cervical cancer and grade 3 cervical intraepithelial neoplasia incidence: A register-based observational study. Lancet 2021, 398, 2084-2092. [CrossRef]

20. Ma, Y.; Wang, C.; Liu, F.; Lian, G.; Li, S.; He, Q.; Li, T. Human papillomavirus vaccination coverage and knowledge, perceptions and influencing factors among university students in Guangzhou, China. Hum. Vaccines Immunother. 2021, 17, 3603-3612. [CrossRef]

21. Patseadou, M.; Galli-Tsinopoulou, A.; Goulis, D.G.; Arvanitidou, M. Factors associated with the onset of sexual activity among Greek high school students. Eur. J. Contracept. Reprod. Health Care 2010, 15, 357-366. [CrossRef]

22. Feng, S.; Xu, X.; Jin, Y.; Yao, X. Women's Knowledge of Human Papillomavirus (HPV) and Their Attitudes Toward HPV Vaccine: Preparing for HPV Vaccination in China. Asia Pac. J. Public Health 2012, 24, 522-531. [CrossRef]

23. Zou, H.; Wang, W.; Ma, Y.; Wang, Y.; Zhao, F.; Wang, S.; Zhang, S.; Ma, W. How university students view human papillomavirus (HPV) vaccination: A cross-sectional study in Jinan, China. Hum. Vaccines Immunother. 2016, 12, 39-46. [CrossRef]

24. Wang, S.; Zhang, S.; Pan, X.; Ren, Z.; Yang, C.; Wang, Z.; Gao, X.; Li, M.; Zheng, Q.; Ma, W. Human Papillomavirus Vaccine Awareness, Acceptability, and Decision-Making Factors among Chinese College Students. Asian Pac. J. Cancer Prev. 2014, 15, 3239-3245. [CrossRef]

25. Zhu, Y.; Hu, X.; Sheng, C. Survey on college students' cognition and attitude towards HPV vaccine. Today Nurse 2017, 11, 25-27.

26. Napolitano, F.; Napolitano, P.; Liguori, G.; Angelillo, I.F. Human papillomavirus infection and vaccination: Knowledge and attitudes among young males in Italy. Hum. Vaccines Immunother. 2016, 12, 1504-1510. [CrossRef]

27. Liu, Y.; Di, N.; Tao, X. Knowledge, practice and attitude towards HPV vaccination among college students in Beijing, China. Hum. Vaccines Immunother. 2020, 16, 116-123. [CrossRef]

28. Khan, T.M.; Buksh, M.A.; Rehman, I.U.; Saleem, A. Knowledge, attitudes, and perception towards human papillomavirus among university students in Pakistan. Papillomavirus Res. 2016, 2, 122-127. [CrossRef]

29. Kellogg, C.; Shu, J.; Arroyo, A.; Ngoc Tuyen, D.; Wade, N.; Sanchez, E.; Equils, O. A significant portion of college students are not aware of HPV disease and HPV vaccine recommendations. Hum. Vaccines Immunother. 2019, 15, 1760-1766. [CrossRef] 
30. Bianco, A.; Zucco, R.; Nobile, C.G.A.; Pileggi, C.; Pavia, M. Parents Seeking Health-Related Information on the Internet: Cross-Sectional Study. J. Med. Internet Res. 2013, 15, 268-277. [CrossRef]

31. Zucco, R.; Lavano, F.; Anfosso, R.; Bianco, A.; Pileggi, C.; Pavia, M. Internet and social media use for antibiotic-related information seeking: Findings from a survey among adult population in Italy. Int. J. Med Inform. 2018, 111, 131-139. [CrossRef]

32. Napolitano, F.; Napolitano, P.; Angelillo, I.F. Seasonal influenza vaccination in pregnant women: Knowledge, attitudes, and behaviors in Italy. BMC Infect. Dis. 2017, 17, 48. [CrossRef] [PubMed]

33. Deng, C.; Chen, X.; Liu, Y. Human papillomavirus vaccination: Coverage rate, knowledge, acceptance, and associated factors in college students in mainland China. Hum. Vaccines Immunother. 2021, 17, 828-835. [CrossRef] [PubMed]

34. Han, B.; Wang, S.; Wan, Y.; Liu, J.; Zhao, T.; Cui, J.; Zhuang, H.; Cui, F. Has the public lost confidence in vaccines because of a vaccine scandal in China. Vaccine 2019, 37, 5270-5275. [CrossRef] [PubMed]

35. You, D.; Han, L.; Li, L.; Hu, J.; Zimet, G.D.; Alias, H.; Danaee, M.; Cai, L.; Zeng, F.; Wong, L. Human Papillomavirus (HPV) Vaccine Uptake and the Willingness to Receive the HPV Vaccination among Female College Students in China: A Multicenter Study. Vaccines 2020, 8, 31. [CrossRef]

36. Ayandele, O.; Ramos-Vera, C.A.; Iorfa, S.K.; Chovwen, C.O.; Olapegba, P.O. Exploring the Complex Pathways between the Fear of COVID-19 and Preventive Health Behavior among Nigerians: Mediation and Moderation Analyses. Am. J. Trop. Med. Hyg. 2021, 105, 701-707. [CrossRef]

37. Olapegba, P.O.; Chovwen, C.O.; Ayandele, O.; Ramos-Vera, C. Fear of COVID-19 and Preventive Health Behavior: Mediating Role of Post-Traumatic Stress Symptomology and Psychological Distress. Int. J. Ment. Health Addict. 2021. [CrossRef]

38. Maier, C.; Maier, T.; Neagu, C.E.; Vladareanu, R. Romanian adolescents' knowledge and attitudes towards human papillomavirus infection and prophylactic vaccination. Eur. J. Obstet. Gynecol. Reprod. Biol. 2015, 195, 77-82. [CrossRef]

39. Elbasha, E.H.; Dasbach, E.J. Impact of vaccinating boys and men against HPV in the United States. Vaccine 2010, $28,6858-6867$. [CrossRef]

40. Burger, E.A.; Sy, S.; Nygard, M.; Kristiansen, I.S.; Kim, J.J. Prevention of HPV-Related Cancers in Norway: Cost-Effectiveness of Expanding the HPV Vaccination Program to Include Pre-Adolescent Boys. PLoS ONE 2014, 9, e89974.

41. Li, J.; Kang, L.-N.; Qiao, Y.-L. Review of the Cervical Cancer Disease Burden in Mainland China. Asian Pac. J. Cancer Prev. 2011, 12, 1149-1153.

42. Zou, Z.; Fairley, C.K.; Ong, J.J.; Hocking, J.; Canfell, K.; Ma, X.; Chow, E.P.F.; Xu, X.; Zhang, L.; Zhuang, G. Domestic HPV vaccine price and economic returns for cervical cancer prevention in China: A cost-effectiveness analysis. Lancet Glob. Health 2020, 8 , E1335-E1344. [CrossRef] 